\title{
A SYSTEM FOR GENERATING VIRTUAL SEEDS
}

\author{
Y. SAKO ${ }^{1}$; K. FUJIMURA ${ }^{1}$; M.B. MCDONALD ${ }^{2}$; D. JAMES ${ }^{2}$ \\ ${ }^{1}$ Dept. of Computer and Information Science, The Ohio State University, Columbus, OH, 43210, USA. \\ ${ }^{2}$ Dept. of Horticulture and Crop Science, The Ohio State University, Columbus, OH, 43210-1086, USA.
}

\begin{abstract}
Seed analysts need to identify seeds, and seed catalogs are used as a reference to accomplish this task. Conventional seed catalogs supply two-dimensional photographs and handdrawn diagrams. In this study, a new, three-dimensional representation of seeds is developed to supplement these traditional photographs and drawings. QuickTime VR is a promising method for viewing three-dimensional objects on a computer screen. It permits manipulation of an object by rotating and viewing it from any pre-specified angle at an interactive speed, allowing the viewer the sense of examining a hand-held object. In this study, QuickTime VR object movies of seeds were created as interactive "movies" of seeds that can be rotated and scaled to give the viewer the sensation of examining actual seeds. This approach allows the examination of virtual seeds from any angle, permitting more accurate identification of seeds by seed analysts.
\end{abstract}

Key Words: seed catalog, computer-aided visualization, seed identification, vision imaging, seed purity

\section{SISTEMA PARA GERAÇÃO DE IMAGENS VIRTUAIS DE SEMENTES}

RESUMO: Os analistas precisam identificar as sementes e utilizam como referência catálogos específicos. Os catálogos geralmente apresentam fotografias bidimensionais e diagramas manuais. Neste estudo, foi desenvolvida uma nova representação tridimensional das sementes como suplementação aos materiais de apoio tradicionais. "QuickTime VR" é um método promissor para a visualização de objetos em três dimensões na tela do computador, permitindo a movimentação de um objeto através da rotação e visualização, em ângulos pré definidos em uma velocidade interativa. No "QuickTime VR" foram criadas imagens interativas que podem ser rotacionadas e dimensionadas dando ao observador a sensação de estar examinando a própria semente. Este procedimento permite o exame de "sementes virtuais" sob qualquer ângulo, permitindo aos analistas de sementes uma identificação mais detalhada.

Descritores: catálogo de sementes, visão computadorizada, identificação de sementes, análise de imagens, pureza física

\section{INTRODUCTION}

Seed analysts use seed catalogs to study features of various seeds and to assist seed identification. Conventional seed catalogs contain two-dimensional photographs or drawings that capture seeds from a limited number of angles (Figure 1).This two-dimensional presentation of seeds has limitations since seeds are threedimensional objects. If seed catalogs contained threedimensional visual representation of seeds, more information could be gained by the viewer. QuickTime VR, a technology for creating image-based virtual environments on a computer screen, is suitable for this task (Loomis, 1998). A QuickTime VR movie is an interactive movie that allows the user to navigate photographic images threedimensionally by use of an input device such as a mouse. There are two kinds of QuickTime VR movies: panoramic and object. In a panoramic movie, the viewer is virtually standing in a scene and looks around. In an object movie, the viewer moves around an object to look at it from various angles (or, equivalently, the viewer is stationary and spins the object). The object movie format is suitable for virtual seeds because the user can virtually rotate and examine the seed from various angles as in real life. In the new generation of seed catalogs being developed, virtual seeds (QuickTime VR object movies of seeds) may supplement and eventually replace two-dimensional photographs and drawings. 


\section{MATERIAL AND METHODS}

Generating virtual seeds: A virtual seed is made by combining an array of two-dimensional images of a seed into a navigable format. The following sequence of steps is used for producing a virtual seed: 1. Pictures of the seed are taken from various angles using a camera or video camera; 2. Images are digitized; 3 . Digitized images are processed so that the object size, position, and rotation axis are uniform throughout the sequence; 4. A QuickTime linear movie is created from the processed images; 5 . The QuickTime linear movie is converted to a virtual seed (QuickTime VR object movie).

Capturing images: Sequences of photographs of the seed are taken from specified elevation angles with a camera or video camera. The number of photographs in each sequence and the number of sequences (rows) are determined by the increment angle (or, the angle created between the seed and adjacent stops). For example, if the increment angle is set at 45 degrees, there is a need to take $360 / 45=8$ photographs per row and $180 / 45+1=5$ rows. (This 45-degree increment angle is arbitrarily chosen for the purpose of description. The increment angle should be 15 degrees or less to create a satisfactory virtual seed.) Figure 2 illustrates this process. a

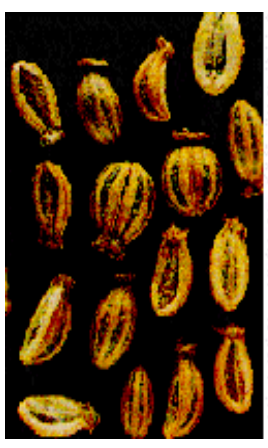

b

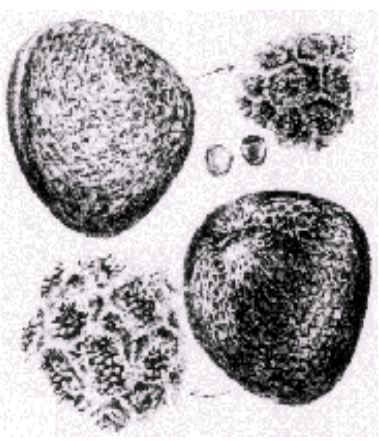

Figure 1 - (a) A photographic image from an existing seed manual (Delorit, 1970) and (b) a drawing from an existing seed handbook (Musil, 1978).
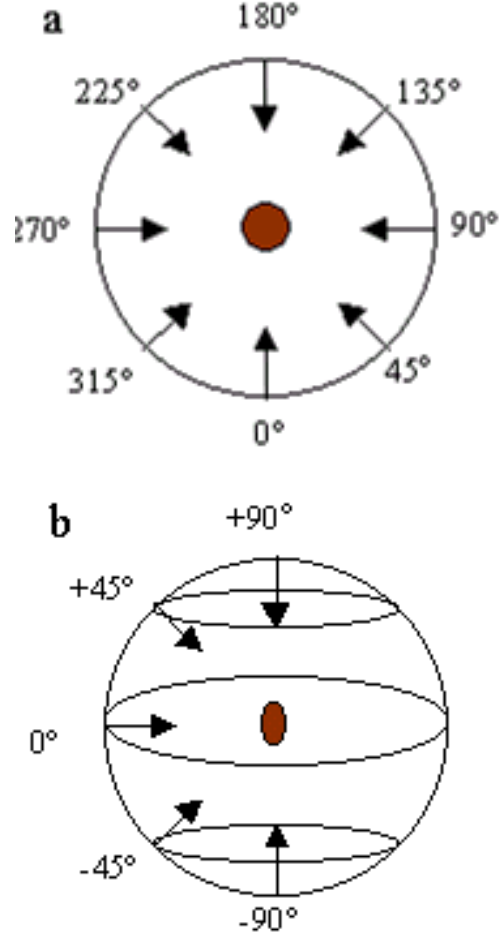

Figure 2 - (a) The seed viewed from the top. Photographs are taken from the eight horizontal angles (at $45^{\circ}$ increment) for each row (elevation angle); (b) The seed viewed from the side. Eight photographs must be taken from each elevation angle labeled $+45^{\circ}, 0^{\circ}$, and $-45^{\circ}$. Only one photograph is needed for $+90^{\circ}$ and $-90^{\circ}$, each.

In order to take photographs of the seed from different horizontal angles, the camera position is fixed and the seed is rotated about a fixed axis on a rotating device such as the center of the second-hand of a small clock. Photographs are taken from various elevation angles by placing the rotating device on an incline (Figure 3). Positioning the camera on the other side or rotating the device by 180 degrees enables capturing photographs from the opposite elevation angle (e.g. the opposite elevation angle of 30 degrees is -30 degrees). For small seeds, the setup is placed under a microscope. 


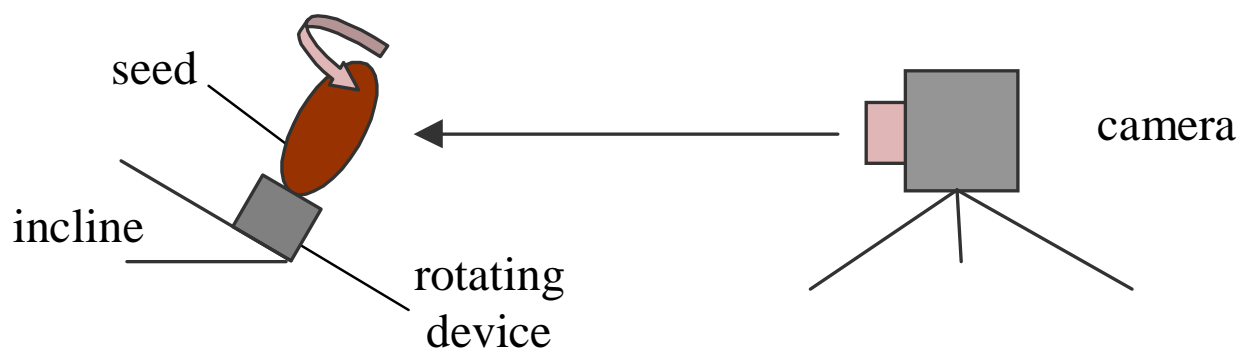

Figure 3 - The setup used for capturing seed images at various angles.

When taking photographs, it is desirable that the distance from the camera to the seed remains the same and that the seed is centered in the frame. In addition, the seed should be attached to the rotation device so that the tips of the seed line up vertically to minimize wobbling. Minor variations in these parameters can be corrected by the software developed in this study that is referred to as VSF (Virtual Seed Factory).

Digitization: This process converts the photographs acquired above into a form capable of being processed by $V S F$. When a conventional camera was used, developed photographs were digitized via scanning and stored on diskettes or on a CD-ROM. When an analog video camera was used to capture images on videotape, the images were digitized by a videocapturing card. If a digital camera/video camera were used, this step was unnecessary since the digitized data were transferred directly to the computer. There are several options for the format of the digitized images: non-compressed format such as BMP or compressed format such as GIF, JPEG, or TIFF. This study used the BMP format. To reproduce the original color of the seed as closely as possible in the final QuickTime VR object movie, as many bits per pixel were retained as possible. Using 24 bits per pixel produced images of excellent quality since up to approximately 16 million colors can be used to represent each pixel.

Processing digitized images: In a QuickTime VR object movie, the viewer can explore the object by virtually moving it in a three-dimensional manner. If an image of the object is out of place, the object size relative to that of the previous frame is different, or the rotation axis is not where it should be, then the viewer does not obtain the sensation of manipulating the object. Thus, the images must be processed and transformed so that the resulting QuickTime VR movie flows from one image to the next. To do this, a graphics application that allows image manipulation (such as Adobe's Photoshop) is used to make djustments to the images until the images appear to produce a smooth sequence. This step was timeconsuming, tedious, and involved guesswork since such graphics applications are not adapted to this task. Therefore, the software developed in this study was designed to make this process easier and more efficient.

Creating a linear movie: The processed images are converted to a QuickTime linear movie. A QuickTime linear movie is a movie format that allows normal playback only. In this step, a movie-authoring tool such as Adobe's Premiere is used. The ordering of images in the linear movie is significant because it determines how images in the final QuickTime VR object movie are connected. The images are stored in QuickTime VR by row-major order. The first sequence of images (array index from [0] to [number of columns per row minus 1]) should be for the topmost row (highest elevation angle). The next sequence of images (array index from [number of columns per row] to [number of columns per row times 2 minus 1]) should be the next lower row, etc.

Creating a QuickTime VR Movie: The linear movie is converted to a virtual seed (QuickTime VR object movie) using conversion software such as Apple's Make QTVR Object.

\section{SOFTWARE TO PROCESS DIGITIZED IMAGES}

As described earlier, several problems exist when capturing images: 1 .the seed might be attached 
to the rotating device in such a way that it wobbles when the sequence of images is turned into a movie; 2. the distance from the seed to the camera might be slightly different for each row due to error in positioning, resulting in differing seed size across the sequences of pictures from different elevation angles; 3 . the center of the seed is not located in the center of the viewfinder of the camera; 4 . the rotation axis is slanted due to the camera being tilted.

$V S F$ is designed to semi-automate the process of making correction to the digitized images. The major tasks in modifying the images are rotating, scaling, and aligning the seed. VSF semi-automates the process of performing these tasks by having the user click two salient points (such as top and bottom tips of the seed) in each image and matches the two pairs of points in successive images so that the object size, position, and rotation axis match relative to each other. The user repeats this process for the remaining images in the sequence. The desired output is a sequence of images in which the seed is rotated, scaled, and positioned correctly to produce a smooth QuickTime VR object movie.

Description of the click-two-points method: The click-two-points method works in three steps: 1. correct the rotation axis; 2 . correct the object size; 3 . correct the object position.

First, the user clicks two salient points on an image. The two points clicked form a line, which is the desired rotation axis for the image. The two points clicked can differ in $\mathrm{x}$-coordinate, making the axis slanted (Figure 4a). The software rotates the image so that the corresponding points make a vertical line after being rotated (Figure $4 b$ ).

Next, the user clicks two points on the next image in the sequence. Rotation is applied to this image as in the previous image. The line segments formed by the points in the two images can be different in length. Therefore, the latter image is scaled to make the line length the same as the previous image (Figures $4 c$ and $4 d$ ).

These steps fix the object size. Finally, the two points clicked by the user must be positioned so the $\mathrm{x}$ - and $\mathrm{y}$-coordinates of the points are the same for all images in the row. This is done by translating the latter image by the correct amount (Figures 4e and 4f).

The above method works for adjusting images across the same row. To ensure that the center of rotation is fixed across all rows, the software calculates the center of rotation for each row by taking the midpoint of the two feature points of an image of the row. The images are translated so that the center of rotation is fixed across all rows (Figures $4 \mathrm{~g}$ and $4 \mathrm{~h})$.

After the center of rotation is fixed, the user can preview the virtual seed by browsing through the images. It may be that the user wants to adjust the object size of a certain row (i.e. the size of the seed seems to change abruptly when browsing across rows - see Figure 5). VSF allows the user to scale all images of a certain row by an interactively specified scale factor.

Finally, all images must be uniformly cropped so that all images have the same dimension and the seed is centered. VSF facilitates this task by permitting the user to interactively specify a crop window whose center automatically coincides with the center of rotation.

Target platform and development tools: $V S F$ was developed for Windows 95 using Microsoft's Visual $\mathrm{C}++$ 4.0. Microsoft Foundation Class (MFC), a set of classes for Windows API, was used to simplify the programming task. The principal reason for developing this software for Windows 95 is that Apple, the creator of QuickTime VR technology, does not make a QuickTime VR authoring tool for Windows 95. In addition, Windows 95 is a popular operating system for most personal computers.

\section{RESULTS}

By applying VSF, virtual seeds (QuickTime VR object movies of seeds) were produced for the following seeds: onion, ragweed, carrot, and wild carrot (Figure 6).

Since virtual seeds cannot be viewed interactively on a sheet of paper, the reader is encouraged to view the seeds on a computer. The following web page contains the virtual seeds presented here (and possibly some others since the database is growing) as well as information on how to obtain $V S F$ :

http://www.cis.ohio-state.edu/ ysako/seed/

In order to view these movies, QuickTime software must be installed on the computer. The software is available for Windows and Macintosh at:

http://www.apple.com/quicktime/ 

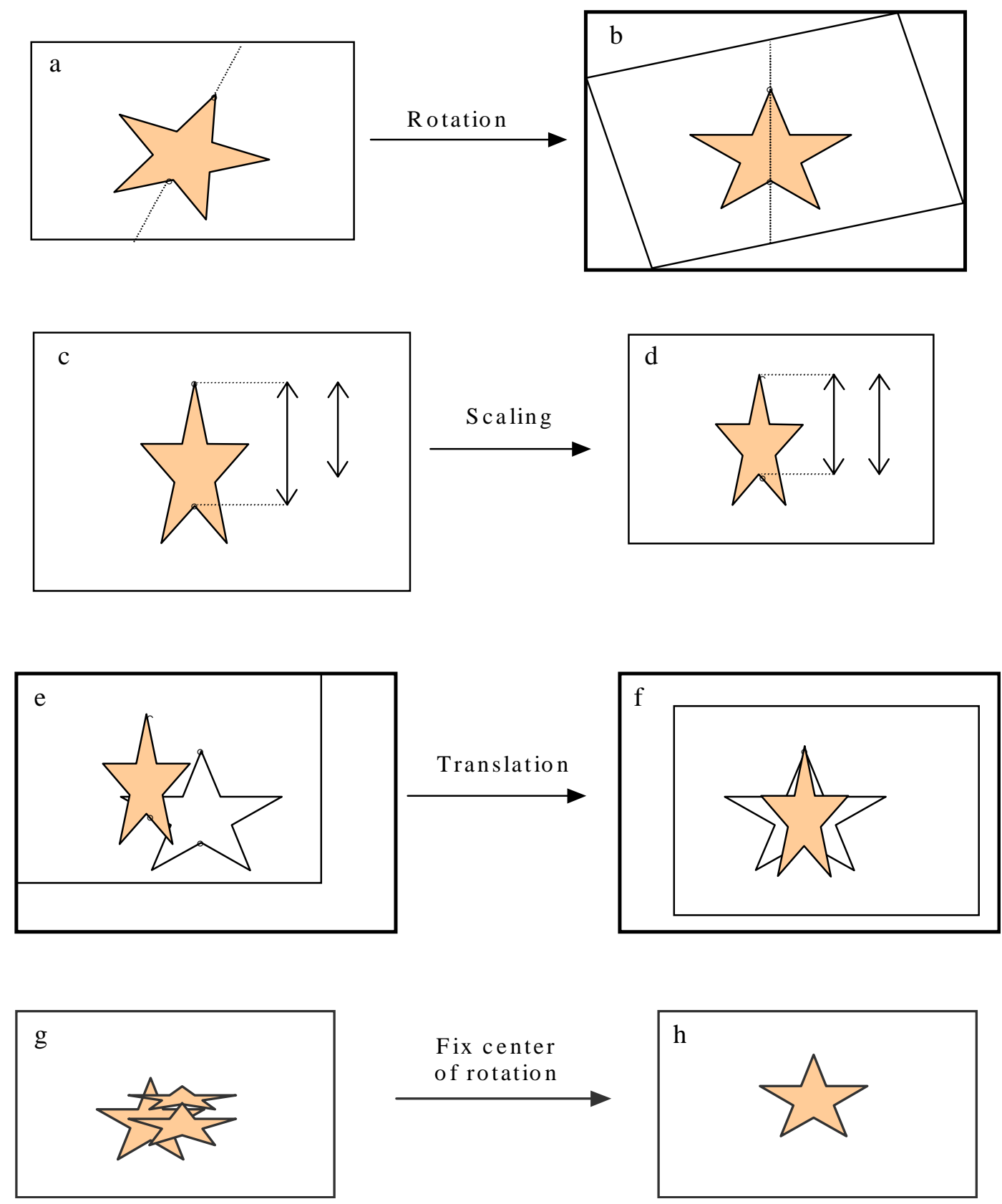

Figure 4 - When browsing across rows (different elevation angles), the size of the seed may seem to change abruptly. In this example, Row 3 (0-degree elevation angle) must be scaled down. 
Row 1 (+60)

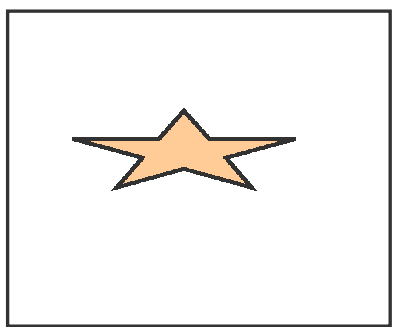

Row $2(+30)$

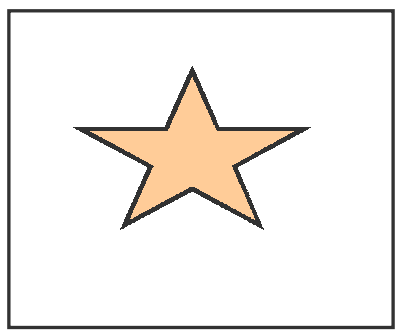

Row 3 (0)

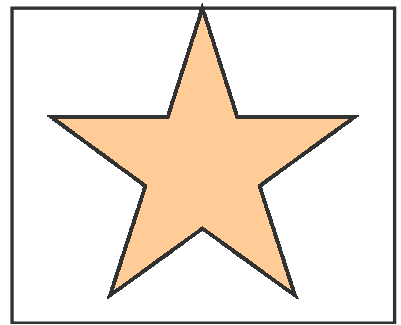

Figure 5 - When browsing across rows (different elevation angles), the size of the seed may seem to change abruptly. In this example, Row 3 (0-degree elevation angle) must be scaled down.

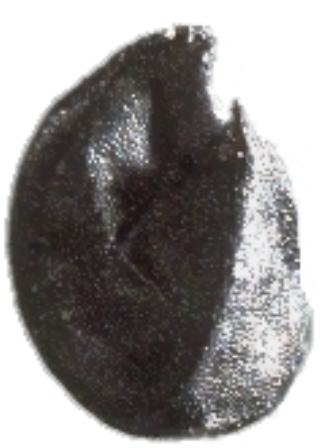

Onion

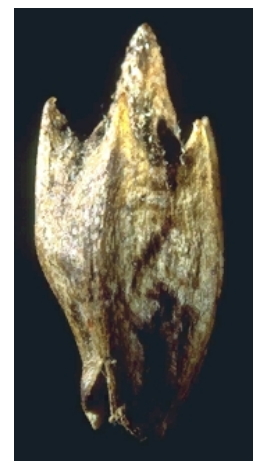

Ragweed

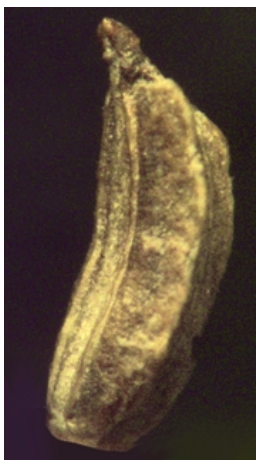

Carrot

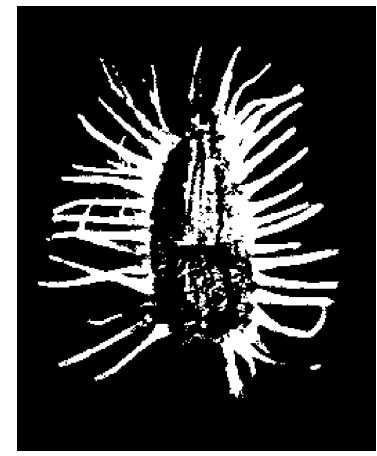

Wild Carrot

Figure 6 - Virtual seeds produced for onion, ragweed, carrot, and wild carrot. See http://www.cis.ohiostate.edu/ ysako/seed/

\section{CONCLUSION}

Significant effort is required to process images manually using standard graphics software. Using VSF, virtual seeds could be produced in a fraction of the time required originally. Instead of spending 5 minutes (which is an optimistic value), the user can simply click points and spend mere 10 seconds or less on each image. A simple calculation yields that more than 30 times less time is spent for processing images when VSF is used.

This decrease in time required for processing images demonstrates the value of this software. The time and effort are reduced further for an average user because the learning curve for using this software is low compared to generic graphics software. Another benefit of the software is that it produces more precise and smoother QuickTime VR object movies since all the computations and precise modifications to the images are accomplished by the software.

$V S F$ proved to be practical and effective for creating virtual seeds. Although the software was originally developed for this task, the software can also be used to create QuickTime VR object movies of cars, models, humans, pets, plants, etc. Since the software is capable of correcting errors such as varying distance, tilt, location in viewfinder, etc., anybody with an interest in creating QuickTime VR object movies can do so by taking pictures with a 
camera, digitizing the pictures, using this software to process the digitized pictures, and putting the pictures together by other third-party software. The development of this software allows inexpensive creation of QuickTime VR object movies with only a camera and a personal computer and no specialized hardware.

The initial objective of virtual seed catalogs is to serve as visualization tools. Other applications are possible as the number of virtual seeds grows in a virtual seed catalog. For example, a system that automatically recognizes seeds given a view or a text description of a seed can be created. Because virtual seed catalogs contain numerous views of seeds, more accurate and robust recognition system can be realized, facilitating improved training of seed analysts and better seed identification.

\section{ACKNOWLEDGEMENTS}

The effort of the OARDC photographer Ken Chamberlain who provided photographs of numerous seeds is recognized. In addition, appreciation is extended to Mitch Moser (Communications and Technology) for capturing images of seeds on videotapes and digitizing them. Lastly, I thank Jeremy Loomis (Department of Computer and Informatioin Science) for his initial work on this project.

\section{REFERENCES}

CHEN, S.E. QuickTime VR: an image-based approach to virtual environment navigation. In: SIGGRAPH'95. s.1.: s.ed., 1995. p.29-38.

DELORIT, R.J. An illustrated taxonomy manual of weed seeds. River Falls: Agronomy Publications, 1970.

FOLEY, J.D. et al. Computer graphics: principles and practice. 2. ed. Reading: Addison-Wesley, 1990. 1174p.

LOOMIS, J.J., K. FUJIMURA, M. MCDONALD, D. JAMES and M. BENNETT. 1998. Using computer graphics for three-dimensional seed cataloging. Seed Science and Technology, 1998. / In press/

MUSIL, A. F. Identification of crop and weed seeds. Agricultural Handbook, p.219, 1978.

Recebido para publicação em 10/07/98

Aceito para publicação em 03/08/98 